\title{
Partial Plantar Fasciotomy Using Endoscope with Inner Two-Channel Portals Produced Better Functional Outcomes Than Mini-Open Procedures for The Treatment of Refractory Plantar Fasciitis
}

Shi-Ming Feng ( $\nabla$ fengshiming_04@163.com )

Xuzhou Central Hospital https://orcid.org/0000-0002-0815-2426

Ai-Guo Wang

Xuzhou Central Hospital

Zai-Yi Zhang

Xuzhou Central Hospital

\section{Technical advance}

Keywords: Endoscopic Partial Plantar Fasciotomy, Refractory Plantar Fasciitis, Inner Two-Channel Portals, Mini-Open Plantar Fasciotomy

Posted Date: October 9th, 2019

DOl: https://doi.org/10.21203/rs.2.15786/v1

License: (c) (1) This work is licensed under a Creative Commons Attribution 4.0 International License.

Read Full License 


\section{Abstract}

Objective: To evaluate the clinical efficacy of partial fasciotomy using two-channel arthroscope in the treatment of refractory plantar fasciitis, and to compare it with the clinical effects of partial fasciotomy using minimally invasive open.

Methods: Sixty-two patients with refractory fasciitis admitted from January 2015 to July 2017 were randomly assigned to the arthroscopic group and the open surgery group. Arthroscopic partial section was performed using endoscope with inner two-channel portals. The open surgery group underwent partial sacral fascia resection with minimally invasive medial incision. Then compare the pain visual analogue scale (VAS), the American foot and ankle surgery association score (AOFAS), the calcaneodynia score (CS), and the medical outcomes short form 36-item (SF-36) health survey between the two groups.

Results: All patients were followed up for at least 24 months, and there was no difference in follow-up between two groups. At the last follow-up, the patient's plantar pain symptoms completely disappeared. There was no recurrence of the bone spurs, and the ankle and foot movements were normal. There was no statistically significant difference in VAS, AOFAS, and CS scores between the two groups. The SF-36 score of the arthroscopy group is significantly higher than the open surgery group.

Conclusions: Arthroscopic partial fascia resection with medial access provides better clinical outcomes than the open minimally-invasive surgery. Arthroscopic partial fasciotomy with the medial access provides a new option better than the open minimally-invasive surgery for postoperative daily life.

\section{Background}

Tendon fasciitis is one of the main causes of plantar pain. The disease is more common in middle-aged and elderly people. It is a chronical disease and the patients usually has no obvious history of trauma. The incidence rate accounts for about $15 \%$ of all foot diseases.[1,2] Although it is a degenerative disease, its specific pathogenesis is still unclear. Diagnosis relies mainly on clinical examination and developmental processes of the disease. The main discomfort of the patient is the pain in the heel, especially in the first step in the morning and the first step of weight-bearing walking after the break.[3] Although the pain symptoms are significant, affecting the patient's normal walking and quality of life, the pain symptoms can disappear after months of conservative treatment.[4-6]lf the therapeutic effect is not significant after 6 months of conservative treatment, the disease is recognized as refractory fasciitis. Then the surgery is generally required. $[7,8]$ Surgical treatment mainly includes traditional open largeincision surgery, minimally-invasive surgery with small incision, percutaneous minimally-invasive surgery and arthroscopic surgery, the surgical treatment effect is not as what we expect. [9-11] Arthroscopic technique, as a relatively new minimally-invasive technique developed in recent years, has also been gradually applied in the treatment of fasciitis. [12-14] However, the current treatment effect of arthroscopic surgery, especially compared with open minimally-invasive surgery, seems to be rarely 
reported in the literature. The purpose of this study was to investigate the clinical efficacy of arthroscopic treatment of refractory plantar fasciitis with a minimally-invasive small incision.

\section{Methods}

Case inclusion criteria: (1) Patients with confirmed fasciitis have a course of more than 12 months; (2) Normative conservative treatment over 6 months and above, but the efficiency is not satisfactory; (3) At least 2 mechanical strategies or a drug is used in conservative treatment; (4) Preoperative MRI scan of the heel is performed to confirm fascial edema and thickening; (5) Preoperative color ultrasonic diagnosis of legs is carried out to confirm no vascular diseases; (6) The onset of disease occurs unilaterally, and the patients received the first surgical treatment of fasciitis; (7) The patients have complete surgical and follow-up data, and the follow-up time is not less than 24 months.

Case exclusion criteria: (1) The disease co-occurs with other diseases of the foot; (2) Previous primary or secondary factors lead to fascia defect; (3) Conservative treatment for only rehabilitation exercise is required; (4) Case data or follow-up data are not complete; (5) The disease is concomitant with severe systemic diseases, and the patients are unable to tolerate surgery; (6) The heel pain is caused by calcaneus stress fracture, heel fat pad syndrome, achilles tendinitis, lateral plantar nerve compression syndrome, tumor, trauma and infection; (7) The skin around the heel is infected, and the operator cannot be operated normally.

From January 2015 to July 2017, 62 cases (62 feet) were included according to the above inclusion and exclusion criteria. The above patients were randomized according to the random number table (33 cases in the arthroscopy group and 29 cases in the open surgery group). There are no difference in age, body mass index, preoperative VAS, AOFAS, CS [15] and SF-36 scores between the two groups (Table 1). The arthroscopic surgery group was performed by an experienced senior physician; the open surgery group was performed by a senior physician with many-year experience in minimally-invasive treatment of fasciitis. The two doctors were unaware of each other's research. This study was approved by the institutional review boards of our hospital (ZXYY-2015061). Informed consent and Health Insurance Portability and Accountabilty Act consents were obtained from each patient.

The study was approved by the Hospital Ethics Committee, Informed Consent and Health Insurance Portability and Accountability Act. Consent was obtained from each patient.

\section{Procedures}

The patient takes the supine position. The doctors used the middle thigh airbag inflatable tourniquet to stop bleeding. The foot is placed flat on the operating bed, and the affected hip flexes externally, the knee flexes. The cotton can be placed at the bottom of the affected foot if necessary. Make the inner side of the affected foot lie flat on the operating table. 
Arthroscopic surgery group: in the level of patellofemoral calcaneus (the inner side of the tendon was red and white), gave a proximal $0.5 \mathrm{~cm}$ incision. The vascular straight forceps were inserted, and the artificial cavity was bluntly separated to the tendon. At the distal $2 \mathrm{~cm}$ level of the above incision, a distal incision of about $0.5 \mathrm{~cm}$ in length was performed at the red-white meat place, and the vascular straight forceps were used to bluntly separate to the temporal fascia. Inserted a $4.0 \mathrm{~mm} 30^{\circ}$ arthroscope into the proximal incision to explore the condition around the fascia. Inserted the planer head into the distal incision, cleaned the field of view, preserved the fat tissue of the foot as much as possible, and only removed some tissue blocking the operation. The lens and planer could be exchanged for better viewing and cleaning of the tissue surrounding the fascia. After cutting $1 / 2$ of the inner side in the patellofemoral calcaneus with a planer, achieved the above and below fascia thoroughly clean and loosen. If the calcaneus spur above the fascia is existed, the nucleus pliers or electric grinder is used for cleaning. Exchanged lenses and planers to better cleanse and loosen the fascia tissue. If necessary, the superficial fasciae of abductor muscles, short and small toes could be released. Finally, the plasma cutter head was used to stop bleeding completely. Loosed the tourniquet, completely stopped the bleeding under the microscope, and then closed the wound. (Figure 1) On the second day after surgery, the patient walked normally and exercised.

Open minimally invasive group: [16] In the inner of the tendon (about the center of fascia, where the flesh is red and white), a longitudinal incision of about $4.0 \mathrm{~cm}$ is cut. This incision can fully retain the entire plantar structure without damaging the load-bearing parts of the heel. After cleaning the inflammatory tissue around the fascial rim, about $1 \mathrm{~cm}$ tissue was removed from the medial part of the fascia and the lateral part was released. If a calcaneus spur existed, remove it completely. The postoperative patient was maintained in a non-weighted state for 2 weeks using a controlled ankle motion walker (CAM) for 2 weeks, and the patient was allowed to bear weight gradually in the normal shoes for the next 2 weeks.

\section{Outcome Measures}

All measurements were performed by an experienced surgical doctor who had no knowledge of the procedure. The VAS, AOFAS, CS, and SF-36 scores of patients were mainly observed.

\section{Statistical Analysis}

All calculations were made using SPSS version 17.0 software (SPSS, Inc., Chicago, IL.). Quantitative variables were expressed as means and standard deviations. The pre- and post-operative scores of VAS/AOFAS/CS and SF-36 were compared using the Student $t$ test. Significance level was set at 5 percent and $p<0.05$ was considered statistically significant.

\section{Results}


In both groups, 62 cases were successful, and the procedure was smooth. There were no early complications such as vascular/nerve injury and incision complications. At the last follow-up, there was no long-term complications (sinus, scar contracture, scar tingling, neuroma, and recurrence of heel bone spurs, etc.). After an average of 38.19 months of follow-up in the arthroscopy group, VAS decreased from $62.37 \mathrm{~mm}$ to $4.82 \mathrm{~mm}$ in pre-surgery, AOFAS increased from 69.84 points in pre-surgery to 95.17 points in post-surgery, and the CS score increased from 42.18 points in pre-surgery to 96.33 points in post-surgery, SF-36 increased from 91.29 points in pre-surgery to 118.83 points in post-surgery. The open surgery group was followed up for 37.87 months (the follow-up time was not statistically different from the arthroscopy group), the VAS decreased from $60.21 \mathrm{~mm}$ in pre-surgery to $5.06 \mathrm{~mm}$, and the AOFAS increased from 70.06 points in pre-surgery to 92.66 points in post-operation, the CS score increased from 45.73 points in pre-surgery to 93.28 points in post-surgery, and SF-36 increased from 93.17 points in presurgery to 110.27 points in post-surgery. The arthroscopy group and the open group obtained the same follow-up results (no statistical difference) in the VAS/AOFAS/CS score, but the SF-36 score in the arthroscopy group was significantly higher than that in the open group. (Table 2) There was no recurrence of heel pain in the arthroscopy group, and 2 cases of recurrence of heel pain occurred in the open group (in the 14th month after surgery and 17th month after surgery, respectively). The two patients recovered by gastrocnemius pulling function exercise in the following days.

\section{Discussion}

The heel is an important part supporting and coordinating daily exercise. The fascia, as a strong ligament structure of the heel, plays an important physiological role in maintaining the medial longitudinal arch of feet and stabilizing them during walking. $[17,18]$ Calcaneus fasciitis commonly happened in chronicallystrained diseases. With the rise of middle-aged and old-aged fitness, the incidence of this disease exploded. $[19,20]$ Pain in the heel has severely affected the quality of life and the fitness of middle-aged and elderly patients. Most patients with fasciitis have a satisfactory clinical effect after 6-month physical therapy and medication, especially combined with platelet-rich plasma.[21-23] Patients with insignificant effects are diagnosed as ones with refractory fasciitis, requiring surgical intervention. At present, the surgical treatment of refractory fasciitis is classified into open surgery and minimally invasive surgery. $[16,24,25]$ Through the open small incision of the fascia, which is a classic surgical treatment of refractory fasciitis, satisfactory postoperative results were obtained in previous studies; In Chou's research,[26] ninety-one patients with fasciitis were treated with surgery. After 12 months of follow-up, the AOFAS score increased from 46.00 to 91.67 , and the postoperative functional satisfaction reached $89 \%$. In MacInnes's study,[27] partial detachment/incision of the fascia were implemented by conventional open surgery in 30 patients with fasciitis. After 80 months of follow-up, $79 \%$ of patients were satisfied about the results. No patient had associated wound complications. However, with the accelerated pace of life and the increasing pursuit of aesthetics, minimally invasive techniques have become the first choice for patients. The use of arthroscopic technique to treat fasciitis is one of the hot spots in recent years. Because the arthroscopy is known as the third eye of humans, it can achieve precise and minimallyinvasive treatment of lesions.[28-30] After the treatment in this study, the patients in the arthroscopy 
group can walk normally and return to normal life on the second day after surgery, while the traditional incision surgery group needs a transition period (about 2 weeks for walking). Partial resection of the calcaneus fascia under two-channel arthroscope in plantar fasciitis patients is a new and innovative technique that has been reported and clinically applied in recent years.[31] But whether it can achieve the therapeutic effect of traditional surgery or even beyond them is currently unknown. In our study, 33 patients in the medial two-channel arthroscopic group were followed up for 38.19 months, and the same clinical results were obtained in the VAS, AOFAS, and CS scores as the open surgery group. Even, the SF36 score of arthroscopic group was better than that of the open surgery group, the surgical incision was smaller, and the postoperative functional exercise was earlier. There were no postoperative complications.

In order to achieve the desired therapeutic effect, when the inner two-channel arthroscopic technique was adopted to treat the recalcitrant plantar fasciitis, the following points need to be paid attention to: (1) the surgical approach is recommended in the lateral medial of the foot, which is beneficial to arthroscopic instruments, operation, and identification of tendon fasciae after the arthroscopic head is inserted; (2) The distal access of the arthroscope is recommended to be $2 \mathrm{~cm}$ away from the proximal access. If it's too close, it is not conducive to the operation and exposure of tissues surrounding the fascia; If it's too far, it is not conducive to the detection and cleaning of the upper part of the fascia, and complete resection of the calcaneus spur; (3) If the view of arthroscopy is limited, improving strategies to better display the visual field can be used, such as the radiofrequency, increasing liquid-perfusing pressure and a small incision of the fat tissue. Do not excessive removal of the fat tissue in case of the fat to be too thin; (4) Complete cleansing and loosening of the tissue above or below the fascia can be performed. If necessary, the inner $1 / 2$ of the fascia can be removed. Although some scholars obtained satisfactory clinical results after they completely cut off the fascia, but complete cutting the plantar fascia may affect the stability of the longitudinal arch;[32] (5) Although the calcaneus spur is not the main cause of fasciitis, the calcaneus may cause the aggravation of fascial inflammation. Therefore, it is recommended to perform a calcaneus spur resection in patients with it;[33,34] (6) Exchanging the lens and planer channel can be performed to observe omnidirectionally and treat fascia lesions; (7) Loosening fasciae of abductor muscles in the big and/or small toe can be performed to detect the plantar outer nerves and to confirm the diagnosis; (8) After surgery, it is recommended to use a plasma cutter to perform thorough microscopic hemostasis, which can help to prevent the recurrence of disease caused by the mechanical operations of bleeding tissue.

The two-channel arthroscopy for the treatment of refractory plantar fasciitis has the following advantages: (1) The surgical trauma is small, and only two incisions about $0.5 \mathrm{~cm}$ are produced to complete the loosening of the fascia and the resection of calcaneus spur; (2) The treatment is more precise, and could deal with small lesions of fascia tissues; (3) Compared with traditionally internal and external surgery, this procedure has a wider operating space and view field, which can display the lesions of inner and outer sides more clearly; (4) The lesions of the fasciae can be clearly displayed to selectively excise; (5) The calcaneus spur can be directly treated, avoiding traditional C-arm fluoroscopy and saving the operational time. (6) Postoperative recovery is fast. After 2 days, the patient can fully exercise bearing weight, enhancing his/her self-confidence and satisfaction and shortening the recovery period. However, 
this study has the following shortcomings: the sample size is relatively small; the follow-up time is short, and the results may vary as the sample size and follow-up time increase. in addition, the evaluating result of the surgery is impacted by subjective judgement of patients.

\section{Conclusions}

The internal double-channel arthroscopic technique has the strengths of small surgical trauma, precise treatment and impeccable functions. It is an effective treatment for recalcitrant plantar fasciitis, possessing better functional results than the open surgery.

\section{Declarations}

\section{Acknowledgements}

Not applicable.

\section{Funding}

This study was supported by grants from the Jiangsu Provincial Medical Youth Talent Program (QNRC2016393) and Six Talent Peaks Project in Jiangsu Province (2019-WSW-173).

\section{Availability of data and materials}

All data generated or analyzed during this study are included in this published article. Shi-Ming Feng and Ai-Guo Wang can be contacted to request the raw data.

\section{Authors' contributions}

ZZY performed the follow-up experiments. FSM gave the experiment guidance during this study and revised this paper critically for important intellectual content. WAG analyzed and interpreted the data and was a major contributor in writing the manuscript. All authors read and approved the final manuscript.

\section{Ethics approval and consent to participate}

The study was approved by the clinical research ethics committee of the Xuzhou Central Hospital. Reference No. ZXYY-2015061. Written informed consent was obtained by all participants.

\section{Consent for publication}

Not applicable. 


\section{Competing interests}

The authors declare that they have no competing interests.

\section{References}

1. Hansen L, Krogh TP, Ellingsen T, Bolvig L, Fredberg U. Long-Term Prognosis of Plantar Fasciitis: A 5to 15-Year Follow-up Study of 174 Patients With Ultrasound Examination. Orthop J Sports Med. 2018;6:2325967118757983.

2. Njawaya MM, Moses B, Martens D, Orchard JJ, Driscoll T, Negrine J, Orchard JW. Ultrasound Guidance Does Not Improve the Results of Shock Wave for Plantar Fasciitis or Calcific Achilles Tendinopathy: A Randomized Control Trial. Clin J Sport Med. 2018;28:21-7.

3. Petraglia F, Ramazzina I, Costantino C. Plantar fasciitis in athletes: diagnostic and treatment strategies. A systematic review. Muscles Ligaments Tendons J. 2017;7:107-18.

4. Heigh E, Bohman L, Briskin G, Slayton M, Amodei R, Compton K, Baravarian B. Intense Therapeutic Ultrasound for Treatment of Chronic Plantar Fasciitis: A Pivotal Study Exploring Efficacy, Safety, and Patient Tolerance. J Foot Ankle Surg. 2019;58:519-27.

5. Al-Boloushi Z, López-Royo MP, Arian M, Gómez-Trullén EM, Herrero P. Minimally invasive non-surgical management of plantar fasciitis: A systematic review. J Bodyw Mov Ther. 2019;23:122-37.

6. Chen $\mathrm{CM}$, Lee M, Lin $\mathrm{CH}$, Chang $\mathrm{CH}$, Lin $\mathrm{CH}$. Comparative efficacy of corticosteroid injection and noninvasive treatments for plantar fasciitis: a systematic review and meta-analysis. Sci Rep. 2018;8:4033.

7. Saxena A, Hong BK, Yun AS, Maffulli N, Gerdesmeyer L. Treatment of Plantar Fasciitis With Radial Soundwave "Early" Is Better Than After 6 Months: A Pilot Study. J Foot Ankle Surg. 2017;56:950-3.

8. Fraser JJ, Glaviano NR, Hertel J. Utilization of Physical Therapy Intervention Among Patients With Plantar Fasciitis in the United States. J Orthop Sports Phys Ther. 2017;47:49-55.

9. Wheeler P, Boyd K, Shipton M. Surgery for Patients With Recalcitrant Plantar Fasciitis: Good Results at Short-, Medium-, and Long-term Follow-up. Orthop J Sports Med. 2014;2:2325967114527901.

10. Monteagudo M, Maceira E, Garcia-Virto V, Canosa R. Chronic plantar fasciitis: plantar fasciotomy versus gastrocnemius recession. Int Orthop. 2013;37:1845-50.

11. Yanbin X, Haikun C, Xiaofeng J, Wanshan Y, Shuangping L. Treatment of Chronic Plantar Fasciitis With Percutaneous Latticed Plantar Fasciotomy. J Foot Ankle Surg. 2015;54:856-9.

12. Mulhern JL, Protzman NM, Summers NJ, Brigido SA. Clinical Outcomes Following an Open Gastrocnemius Recession Combined With an Endoscopic Plantar Fasciotomy. Foot Ankle Spec. 201;11:330-4.

13. Wang W, Rikhraj IS, Chou ACC, Chong HC, Koo KOT. Endoscopic Plantar Fasciotomy vs Open Radiofrequency Microtenotomy for Recalcitrant Plantar Fasciitis. Foot Ankle Int. 2018;39:11-7. 
14. Miyamoto W, Yasui Y, Miki S, Kawano H, Takao M. Endoscopic plantar fascia release via a suprafascial approach is effective for intractable plantar fasciitis. Knee Surg Sports Traumatol Arthrosc. 2018;26:3124-8.

15. Rowe CR囚Sakellarides HT囚Freeman PA囚 Sorbie C. Fractures of the Os Calcis: A Long-Term Follow-up Study of 146 Patients. JAMA, 1963;184: 920-3.

16. Gibbons R, Mackie KE, Beveridge T, Hince D, Ammon P. Evaluation of Long-term Outcomes Following Plantar Fasciotomy. Foot Ankle Int. 2018;39:1312-9.

17. Guo JC, Wang LZ, Mo ZJ, Chen W, Fan YB. Biomechanical analysis of suture locations of the distal plantar fascia in partial foot. Int Orthop. 2015;39:2373-80.

18. Chen YN, Chang CW, Li CT, Chang CH, Lin CF. Finite element analysis of plantar fascia during walking: a quasi-static simulation. Foot Ankle Int. 2015;36:90-7.

19. Kaşkari D, Yücel AE, Ağildere M. The prevalence of spondyloarthropathy in fibromyalgia patients. Mod Rheumatol. 2017;27:875-80.

20. Rastegar S, Baradaran Mahdavi S, Hoseinzadeh B, Badiei S. Comparison of dry needling and steroid injection in the treatment of plantar fasciitis: a single-blind randomized clinical trial. Int Orthop. 2018;42:109-16.

21. Chen YJ, Wu YC, Tu YK, Cheng JW, Tsai WC, Yu TY. Autologous Blood-Derived Products Compared With Corticosteroids for Treatment of Plantar Fasciopathy: A Systematic Review and Meta-Analysis. Am J Phys Med Rehabil. 2019;98:343-52.

22. Li H, Lv H, Lin T. Comparison of efficacy of eight treatments for plantar fasciitis: A network metaanalysis. J Cell Physiol. 2018;234:860-70.

23. Katzap Y, Haidukov M, Berland OM, Itzhak RB, Kalichman L. Additive Effect of Therapeutic Ultrasound in the Treatment of Plantar Fasciitis: A Randomized Controlled Trial. J Orthop Sports Phys Ther. 2018;48:847-55.

24. Sahu RL. Percutaneous planter fasciitis release under local anesthesia: A prospective study. Chin J Traumatol. 2017;20:87-9.

25. Whittaker GA, Munteanu SE, Menz HB, Bonanno DR, Gerrard JM, Landorf KB. Corticosteroid injection for plantar heel pain: a systematic review and meta-analysis. BMC Musculoskelet Disord. 2019;20(1):378.

26. Chou AC, Ng SY, Su DH, Singh IR, Koo K. Radiofrequency microtenotomy is as effective as plantar fasciotomy in the treatment of recalcitrant plantar fasciitis. Foot Ankle Surg. 2016;22:270-3.

27. Maclnnes A, Roberts SC, Kimpton J, Pillai A. Long-Term Outcome of Open Plantar Fascia Release. Foot Ankle Int. 2016;37:17-23.

28. Çatal B, Keskinbora M, Uysal MA, Şahin M, Gulabi D, Demiralp B. Endoscopic Plantar Fasciotomy; Deep Fascial Versus Superficial Fascial Approach: A Prospective Randomized Study. J Foot Ankle Surg. 2017;56:1001-8. 
29. Lui TH. Endoscopic Decompression of the First Branch of the Lateral Plantar Nerve and Release of the Plantar Aponeurosis for Chronic Heel Pain. Arthrosc Tech. 2016;5:e589-94.

30. Cottom JM, Baker JS. Endoscopic Plantar Fascia Debridement for Chronic Plantar Fasciitis. Clin Podiatr Med Surg. 2016;33:545-51.

31. Cottom JM, Maker JM, Richardson P, Baker JS. Endoscopic Debridement for Treatment of Chronic Plantar Fasciitis: An Innovative Technique and Prospective Study of 46 Consecutive Patients. J Foot Ankle Surg. 2016;55:748-52.

32. De Prado M, Cuervas-Mons M, De Prado V, Golanó P, Vaquero J. Does the minimally invasive complete plantar fasciotomy result in deformity of the Plantar arch? A prospective study. Foot Ankle Surg. 2019;doi: 10.1016/j.fas.2019.04.010.

33. Othman AM, Hegazy IH. Endoscopic plantar fasciotomy versus injection of platelet-rich plasma for resistant plantar fasciopathy. J Orthop. 2015;12:S176-81.

34. Nery C, Raduan F, Mansur N, Baunfeld D, Del Buono A, Maffulli N. Endoscopic approach for plantar fasciopathy: a long-term retrospective study. Int Orthop. 2013;37:1151-6.

\section{Tables}

Table 1 Characterization of the Sample

\begin{tabular}{lccc}
\hline Variable & Arthroscopic Group $(\mathrm{n}=33)$ & Open Group & $P^{*}$ Value \\
& & $(\mathrm{n}=29)$ & \\
\hline Age, yr & $57.25 \pm 7.13$ & $55.81 \pm 8.87$ & $0.448 \ddagger$ \\
Sex & & & \\
Male & 12 & 11 & $0.899 \dagger$ \\
Female & 21 & 18 & \\
BMI, kg/m ${ }^{2}$ & $29.16 \pm 4.33$ & $27.87 \pm 3.72$ & $0.212 \ddagger$ \\
Side & & & \\
Right & 19 & 16 & $0.849 \dagger$ \\
Left & 14 & 13 & \\
VAS, mm & $62.37 \pm 18.26$ & $60.21 \pm 15.69$ & $0.618 \ddagger$ \\
AOFAS & $69.84 \pm 12.37$ & $70.06 \pm 11.60$ & $0.943 \ddagger$ \\
CS & $42.18 \pm 10.84$ & $45.73 \pm 11.71$ & $0.223 \ddagger$ \\
SF-36 & $91.29 \pm 9.73$ & $93.17 \pm 10.25$ & $0.464 \ddagger$ \\
Disease duration, mo & $16.98 \pm 4.35$ & $15.63 \pm 3.47$ & $0.180 \ddagger$ \\
\hline
\end{tabular}


Abbreviations: BMI: Body Mass Index; VAS, Visual analogue scale; AOFAS, American Orthopaedic Foot and Ankle Society; CS, Calcaneodynia Score; SF-36, Short Form Health Survey.

*A value $\mathrm{p}<0.05$ was set as statistically significant.

†Pearson $\chi^{2}$ test.

łt test.

Table 2 Comparison of the Two Groups

\begin{tabular}{cccc}
\hline Variable & Arthroscopic Group $(\mathrm{n}=33)$ & Open Group (n=29) & $P^{*}$ Value \\
\hline VAS, mm & $4.82 \pm 2.30$ & $5.06 \pm 1.74$ & $0.643 \dagger$ \\
AOFAS & $95.17 \pm 8.51$ & $92.66 \pm 10.47$ & $0.309 \dagger$ \\
CS & $96.33 \pm 7.25$ & $93.28 \pm 9.86$ & $0.176 \dagger$ \\
SF-36 & $118.83 \pm 8.22$ & $110.27 \pm 13.51$ & $0.005 \dagger$ \\
Follow-up, mo & $38.19 \pm 9.24$ & $37.87 \pm 8.95$ & $0.890 \dagger$ \\
\hline
\end{tabular}

Abbreviations: VAS, Visual analogue scale; AOFAS, American Orthopaedic Foot and Ankle Society; CS, Calcaneodynia Score; SF-36, Short Form Health Survey.

*A value $\mathrm{p}<0.05$ was set as statistically significant.

$\dagger \mathrm{t}$ test.

\section{Figures}
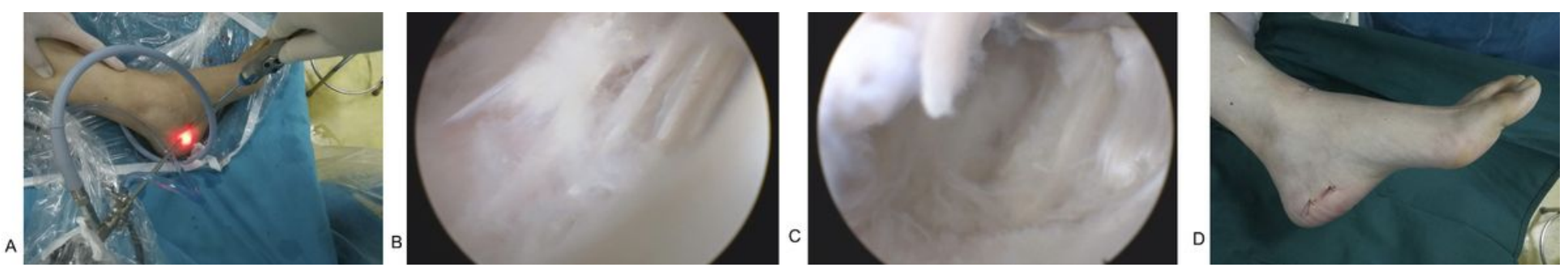


\section{Figure 1}

Refractory plantar fasciitis in the left foot of a 46 years old male worker, who accepted the endoscope treatment with inner two-channel portals underwent 9 months of conservative treatment. A, Intraoperative medial double-channel arthroscopic approach. B, The partial incision of the plantar fascia. C, The plantar fascia after removing inflammatory tissue in the surrounding. D, The appearance of surgical incision after the operation 